\title{
Nonassociative Learning in Invertebrates
}

\author{
John H. Byrne ${ }^{1}$ and Robert D. Hawkins ${ }^{2,3}$ \\ ${ }^{1}$ Department of Neurobiology and Anatomy, The University of Texas Medical School at Houston, \\ Houston, Texas 77030 \\ ${ }^{2}$ Department of Neuroscience, Columbia University, New York, New York 10032 \\ ${ }^{3}$ New York State Psychiatric Institute, New York, New York 10032 \\ Correspondence: john.h.byrne@uth.tmc.edu
}

\begin{abstract}
The simplicity and tractability of the neural circuits mediating behaviors in invertebrates have facilitated the cellular/molecular dissection of neural mechanisms underlying learning. The review has a particular focus on the general principles that have emerged from analyses of an example of nonassociative learning, sensitization in the marine mollusk Aplysia. Learning and memory rely on multiple mechanisms of plasticity at multiple sites of the neuronal circuits, with the relative contribution to memory of the different sites varying as a function of the extent of training and time after training. The same intracellular signaling cascades that induce short-term modifications in synaptic transmission can also be used to induce longterm changes. Although short-term memory relies on covalent modifications of preexisting proteins, long-term memory also requires regulated gene transcription and translation. Maintenance of long-term cellular memory involves both intracellular and extracellular feedback loops, which sustain the regulation of gene expression and the modification of targeted molecules.
\end{abstract}

Learter earning can be divided into two general categories: associative and nonassociative. Associative learning includes classical conditioning and operant conditioning, which are discussed by Hawkins and Byrne (2015). Nonassociative forms of learning include habituation and sensitization. Habituation, the simplest form of learning, is defined as the gradual waning of a behavioral response to a weak or moderate stimulus that is presented repeatedly. Following habituation, the response may be restored to its initial state either passively with time (i.e., spontaneous recovery), or with the presentation of a noxious stimulus. This latter phenomenon is called dishabituation, and its presence distinguishes habituation from simple fatigue (Thompson and Spencer 1966). Sensitization is defined as the enhancement of a behavioral response by strong or repeated stimulation. In one form of sensitization (also referred to as pseudo-conditioning), the behavioral response to a nonhabituated stimulus is enhanced by presentation of a noxious stimulus to another site, similar to dishabituation. In another form of sensitization, a behavioral response is enhanced by the repeated presentation of a moderate to strong intensity stimulus to the same site. This is operationally the opposite phenomenon of habituation, and is referred to as site-specific sensitization.

Editors: Eric R. Kandel, Yadin Dudai, and Mark R. Mayford

Additional Perspectives on Learning and Memory available at www.cshperspectives.org

Copyright (C) 2015 Cold Spring Harbor Laboratory Press; all rights reserved; doi: 10.1101/cshperspect.a021675

Cite this article as Cold Spring Harb Perspect Biol 2015;7:a021675 
Invertebrates offer experimental advantages for analyzing the cellular and molecular mechanisms of learning. For example, many behaviors in invertebrates are mediated by relatively simple neural circuits, which can be analyzed with electrophysiological and optophysiological approaches. Once the circuit is specified, the neural locus for the particular example of learning can be found, and biophysical, biochemical, and molecular approaches can be used to identify mechanisms underlying the change. The relatively large size of some invertebrate neurons allows these analyses to take place at the level of individually identified neurons. In some cases, individual neurons can be surgically removed and assayed for changes in the levels of second messengers, protein phosphorylation, and RNA and protein synthesis. Moreover, peptides and nucleotides can be injected intracellularly or expressed in individual neurons via appropriate vectors.

This review will focus primarily on progress in understanding nonassociative learning in the marine mollusk Aplysia, but many other invertebrates have proven to be valuable model systems for the cellular and molecular analysis of learning and memory (for reviews, see Byrne 1987; Hawkins et al. 1987). Several of these model systems are described within. Each invertebrate model system has its own unique advantages. For example, Aplysia is excellent for applying cell biological approaches to the analysis of learning and memory mechanisms. Other invertebrate model systems, such as Drosophila and Caenorhabditis elegans offer tremendous advantages for obtaining insights into mechanisms of learning and memory through the application of molecular genetic approaches.

\section{NEURAL AND MOLECULAR MECHANISMS OF NONASSOCIATIVE LEARNING IN Aplysia}

The mechanisms of several simple forms of learning have been studied extensively in Aplysia, which has a number of advantages for a reductionist approach (for additional references, see Hawkins et al. 2006). The nervous system of Aplysia consists of $\sim 10,000$ neurons, many of which are uniquely identifiable across indi- vidual animals. Studies of learning have focused primarily on defensive withdrawal reflexes, which have simple circuits consisting of only tens or perhaps hundreds of neurons. Many of those studies have examined the gill- and siphon-withdrawal reflex, in which a light touch to the siphon (an exhalant funnel for the gill) produces contraction of the gill and siphon, whereas others have examined the tail-withdrawal reflex or the tail-elicited siphon-withdrawal reflex. However, the results of all of these studies have generally been similar.

Despite their simplicity, the withdrawal reflexes undergo a variety of different forms of learning including habituation, dishabituation and sensitization. This review focuses on the mechanisms of sensitization. The memory for sensitization has multiple temporal domains that depend to a large extent on the training protocol. Typically, a single noxious stimulus, such as a shock produces short-term sensitization (STS) lasting minutes, whereas repeated shocks can produce long-term sensitization (LTS) lasting days. In addition, an intermediate-term stage has been identified that persists for hours. As we see in the literature, the different temporal phases of memory, the training contingencies that produce them, and even some of the underlying molecular mechanisms are conserved across species including humans.

\section{SHORT- AND INTERMEDIATE-TERM SENSITIZATION}

\section{Mechanisms of Short-Term Sensitization}

During STS, the withdrawal reflex elicited by a weak stimulus to one region of the animal's body is enhanced by a brief electric shock to another region (Carew et al. 1971; Walters et al. 1983b; Antonov et al. 1999; Philips et al. 2011). The neural circuits for many of the withdrawal reflexes consist in part of monosynaptic connections from sensory neurons ( $\mathrm{SN}$ ) to motor neurons $(\mathrm{MN})$, as well as polysynaptic connections involving excitatory and inhibitory interneurons. It is possible to record the activity of these identified neurons and their synaptic connections during learning in semi-intact prepara- 
tions, and thus to examine the contribution of plasticity at different sites in the circuit to behavioral learning. Such experiments have shown, for example, that homosynaptic depression and heterosynaptic facilitation at the SN-MN synapses contribute to habituation, dishabituation, and sensitization of the siphon-withdrawal reflex, and that plasticity at other sites also contributes (Antonov et al. 1999). During sensitization by tail shock, siphon stimulation produces increased siphon withdrawal and increased activity in siphon motor neurons as a result of, in part, two mechanisms (Fig. 1). First, the same peripheral stimulus evokes a greater number of action potentials in the presynaptic SNs (i.e., enhanced excitability). Second, each action potential fired by a SN produces a greater excitatory postsynaptic potential (EPSP) in the MN (i.e., short-term facilitation $[\mathrm{STF}])$. The changes in excitability and synaptic potentials are induced in part by the neuromodulator serotonin (5HT). Both of these changes are mimicked by application of 5-HT, and 5-HT is released from modulatory interneurons during training (Brunelli et al. 1976; Walters et al. 1983b; Glanzman et al. 1989; Mackey et al. 1989; Levenson et al. 1999; Marinesco and Carew 2002; Philips et al. 2011).

The mechanisms of STF at the SN-MN synapses have been examined more extensively in neural analogs of learning in isolated ganglia or in cell culture, in which tail shock is replaced by either nerve shock or application of 5-HT. Early studies (reviewed in Byrne and Kandel 1996) found that STF produced by brief application of 5-HT to rested synapses (an analog of sensitization) involves cyclic adenosine-3-monophosphate (cAMP), protein kinase A (PKA), decreased $\mathrm{K}^{+}$current, and increases in spike width, $\mathrm{Ca}^{2+}$ influx, and transmitter release from the SNs (Fig. 2, short term [ST]). In contrast, STF at depressed synapses (an analog of dishabituation) involves protein kinase $\mathrm{C}$ (PKC), which acts by a spike broadening-independent mechanism, perhaps vesicle mobilization (Fig. 2, DIS). These results suggested that although dishabituation and sensitization both involve facilitation at the $\mathrm{SN}-\mathrm{MN}$ synapses, they may involve fundamentally different mechanisms at the molecular level.

The Relationship between Short- and LongTerm Facilitation, and the Discovery of Intermediate-Term Facilitation

STF involves covalent modifications of proteins in existing synapses. In contrast, five tail shocks or five applications of 5-HT separated by 15 min produce long-term facilitation (LTF), which involves protein and RNA synthesis and

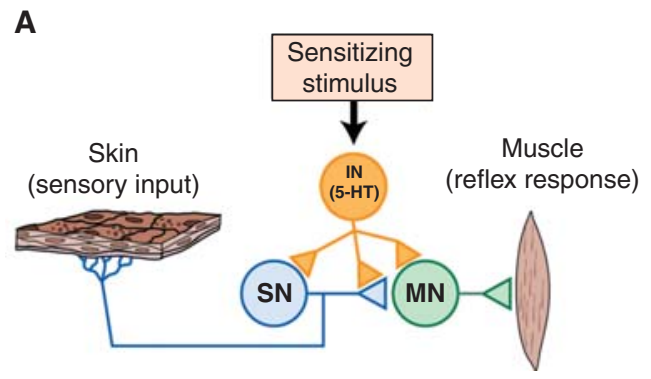

B
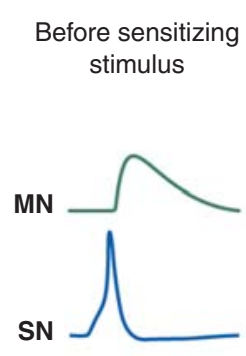

After sensitizing stimulus

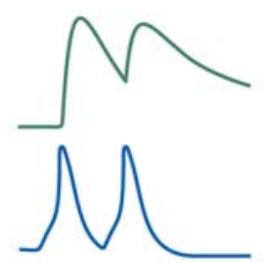

Figure 1. Heterosynaptic facilitation of the sensorimotor connection contributes to sensitization in Aplysia. $(A)$ Sensitizing stimuli activate facilitatory interneurons (IN) that release modulatory transmitters, one of which is 5-HT. The modulator leads to an alteration of the properties of the sensory neuron (SN) and motor neuron $(\mathrm{MN}) .(B)$ The enhanced synaptic input to the MN during sensitization results from enhanced sensory input, partly caused by two mechanisms. First, the same peripheral stimulus can evoke a greater number of action potentials in the presynaptic SN (i.e., enhanced excitability). Second, each action potential fired by an SN produces a stronger synaptic response in the MN (i.e., synaptic facilitation). A component of sensitization is also caused by the effects of 5-HT on the MN. (Based on data from Byrne and Kandel 1996.) 
J.H. Byrne and R.D. Hawkins
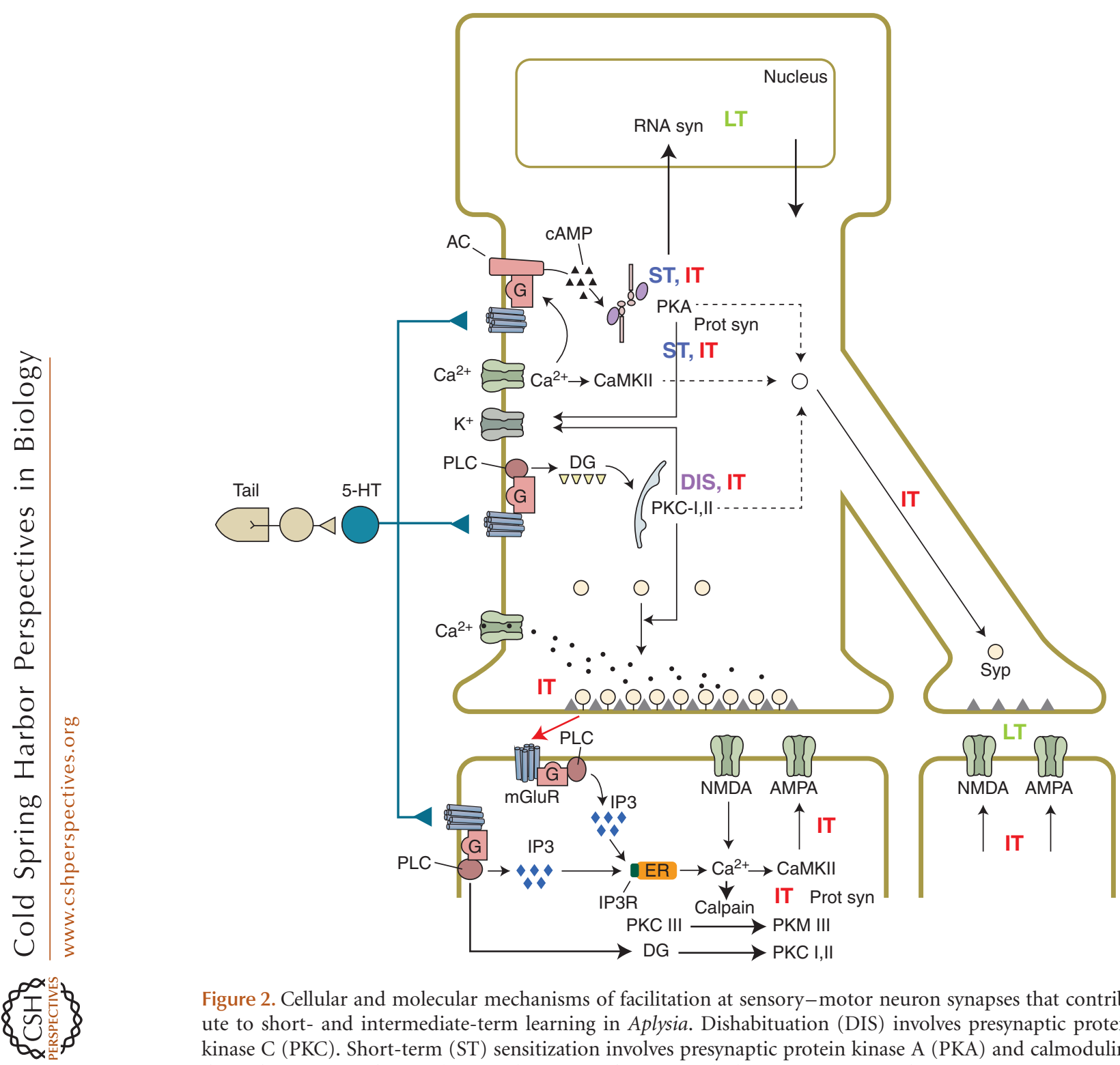

Figure 2. Cellular and molecular mechanisms of facilitation at sensory-motor neuron synapses that contribute to short- and intermediate-term learning in Aplysia. Dishabituation (DIS) involves presynaptic protein kinase C (PKC). Short-term (ST) sensitization involves presynaptic protein kinase A (PKA) and calmodulindependent protein kinase (CaMKII). Intermediate-term (IT) sensitization involves presynaptic PKA and CaMKII or PKC, protein synthesis (prot syn), and spontaneous transmitter release. In addition, it involves postsynaptic mGluRs, CaMKII or PKC, protein synthesis, and membrane insertion of $\alpha$-amino-3-hydroxy-5-methyl-4-isoxazolepropionic acid (AMPA)-like receptors, as well as recruitment of pre- and postsynaptic proteins to new synaptic sites. In contrast, long-term (LT) sensitization involves gene regulation and growth of new synapses. AC, Adenyl cyclase; cAMP, cyclic adenosine-3-monophosphate; DG, diacylglycerol; NMDA, $N$-methyl-D-aspartate; PKM, protein kinase M; PLC, phospholipase C; RNA syn, RNA synthesis. (Based on data in Hawkins et al. 2013.) 
the growth of new synapses, and is thus fundamentally different from STF (Fig. 2, LT). However, it was not clear whether the different stages of plasticity are independent and induced in parallel, or one induces the other in series. Initial studies of facilitation in isolated ganglia suggested that STF and LTF are induced in parallel (Emptage and Carew 1993; Mauelshagen et al. 1996), but similar experiments in culture have suggested that they can be induced, at least partly, in series (Ghirardi et al. 1995).

During the course of these parametric studies of STF and LTF, Ghirardi et al. (1995) also obtained evidence for a third stage that they called intermediate-term facilitation (ITF), which is typically induced by an intermediate level of 5-HT (four to five pulses of a low concentration), persists for hours, and involves PKA and protein synthesis but not RNA synthesis (Fig. 2, intermediate term [IT]). They also found that a higher concentration of 5-HT induces both ITF and LTF, and that the mechanisms of the facilitation depend not only on the time after 5-HT but also on the concentration of 5-HT. For example, facilitation $30 \mathrm{~min}$ after the 5-HT, which is in the intermediate-term time range, can depend on PKA only (with 1 or $10 \mathrm{~nm}$ 5-HT), PKA and protein synthesis (with 50 nм 5-HT), or PKA, protein synthesis, and RNA synthesis (with $100 \mathrm{~nm}$ or $10 \mu \mathrm{m}$ 5-HT). These results illustrate that ITF (like the other stages) is not a unitary entity but rather can involve a number of different mechanisms depending on the protocol and, therefore, suggest that it may be more meaningful to ask whether the mechanisms rather than stages are in parallel or series.

Mechanisms of Induction, Maintenance, and Expression of Intermediate-Term Facilitation

The experiments of Ghirardi et al. (1995) did not distinguish between mechanisms of induction, maintenance, or expression of the facilitation, nor did they examine whether those mechanisms are pre- or postsynaptic. Several groups have addressed those questions using different experimental protocols for ITF. Carew and colleagues found that induction of intermediate- term sensitization (ITS) and ITF with a repeated pulses protocol (five spaced tail shocks or five pulses of 5-HT) requires MAP kinase and protein but not RNA synthesis, and maintenance involves persistent activation of PKA but not PKC (Sutton and Carew 2000; Sutton et al. 2001). In contrast, induction of ITS or ITF with a site-specific protocol (e.g., spike activity in a $\mathrm{SN}$ and simultaneous 5-HT) requires PKC and MAP kinase but not protein synthesis, and maintenance involves persistent activation of PKC rather than PKA (Sutton and Carew 2000; Sutton et al. 2004; Zhao et al. 2006; Shobe et al. 2009). Like mammalian PKC, PKC in Aplysia has three isoforms: conventional (Apl I), novel (Apl II), and atypical (Apl III), which can be cleaved by calpain to form a persistently active kinase, protein kinase M (PKM) (Kruger et al. 1991; Bougie et al. 2009), which is critical for the maintenance of ITF (Bougie et al. 2012). Thus, induction of ITF with either protocol involves multiple mechanisms including activation of MAP kinase, whereas maintenance involves persistent kinase activity, but of different kinases (PKA or PKM) depending on the induction protocol used.

Glanzman and colleagues found that ITF induced by a single 10-min application of 5 -HT involves postsynaptic $\mathrm{Ca}^{2+}$, protein synthesis, and $\alpha$-amino-3-hydroxy-5-methyl-4-isoxazolepropionic acid (AMPA) receptor insertion (Li et al. 2005; Villareal et al. 2007). To investigate those postsynaptic mechanisms independent of presynaptic mechanisms, they examined ITF of the response to focal application of glutamate (the glutamate excitatory potential or Glu-EP) in isolated MNs, and found that it also involves $\mathrm{Ca}^{2+}$, protein synthesis, and AMPA receptor insertion (Chitwood et al. 2001; Villareal et al. 2007). Furthermore, induction of facilitation of the Glu-EP involves calpain-dependent proteolysis of PKC Apl III to form PKM, and maintenance involves persistent activation of PKM (Bougie et al. 2009; Villareal et al. 2009). Subsequent studies have shown that ITF of the SN-MN EPSP also involves postsynaptic PKC Apl III (Bougie et al. 2012).

These studies suggest that, although STF involves presynaptic mechanisms, ITF by $10-$ min 
5-HT involves postsynaptic mechanisms. However, in each case, only one side of the synapse was examined, and it was not known whether the same protocol might involve mechanisms on both sides. Hawkins and colleagues addressed that question, and found that facilitation during STS in the semi-intact siphonwithdrawal preparation involves PKA, calmodulin-dependent protein kinase (CaMK)II, and transient spike broadening in the $\mathrm{SN}$, but it does not involve $\mathrm{Ca}^{2+}$ or CaMKII in the MN and, thus, appears to be entirely presynaptic. The facilitation during ITS also involves PKA, CaMKII, and transient spike broadening in the SN. However, it also involves $\mathrm{Ca}^{2+}$ and CaMKII in the MN and protein synthesis in both neurons, and is thus both pre- and postsynaptic (Antonov et al. 2010).

Similarly, facilitation by 1 -min application of 5-HT in cell culture (an analog of STS) involves PKA and CaMKII in the SN, but it does not involve $\mathrm{Ca}^{2+}$ in the $\mathrm{MN}$ or PKC in either neuron (Jin et al. 2011). In contrast, facilitation by a 10-min application of 5-HT (an analog of intermediate-term sensitization) involves PKC (but not PKA or CaMKII) in the SN, in agreement with previous studies (Byrne and Kandel 1996). In addition, 10-min application of 5-HT involves $\mathrm{Ca}^{2+}$ and CaMKII in the MN and protein synthesis in both neurons and is, thus, both pre- and postsynaptic. Collectively, these results suggest that ITF is the first stage to involve both pre- and postsynaptic molecular mechanisms.

ITF also involves recruitment of synaptic proteins. ITF induced by multiple applications of 5-HT is accompanied by filling of empty presynaptic varicosities with the vesicle-associated protein synaptophysin within $3 \mathrm{~h}$, but not by the formation of new varicosities (Kim et al. 2003). Like facilitation of the postsynaptic potential (PSP) with this protocol (Ghirardi et al. 1995), the increase in clusters of synaptophysin does not persist for $24 \mathrm{~h}$, and does not require protein or RNA synthesis. In contrast, LTF is accompanied by both filling of varicosities and the formation of new varicosities within 12$18 \mathrm{~h}$. Again, like facilitation of the PSP and the increase in varicosities (Bailey et al. 1992), the increase in clusters of synaptophysin during LTF persists for $24 \mathrm{~h}$ and requires protein synthesis. ITF and LTF are also accompanied by increases in clusters of the postsynaptic proteins ApGluR1 and ApNR1 within $12 \mathrm{~h}$, whereas STF is not (Li et al. 2009). These results suggest that the intermediate-term stage is also the first to involve recruitment of both pre- and postsynaptic proteins, which could be initial steps in the formation of new synapses during longterm facilitation.

Spontaneous Transmitter Release from the Presynaptic Neuron Recruits Postsynaptic Mechanisms of Intermediate- and Long-Term Facilitation

If STF is presynaptic but ITF and LTF involve both pre- and postsynaptic mechanisms, how are the postsynaptic mechanisms first recruited? There are at least two possibilities, which are not mutually exclusive: the pre- and postsynaptic mechanisms might be induced by activation of pre- and postsynaptic 5-HTreceptors in parallel, or activation of presynaptic 5-HT receptors might increase spontaneous release of glutamate, which then activates postsynaptic glutamate receptors to induce the postsynaptic mechanisms in series (Fig. 2).

Partly because the postsynaptic mechanisms of ITF are similar to those induced by glutamate release during homosynaptic potentiation (Jin and Hawkins 2003), Jin et al. (2012a,b) investigated the possible role of spontaneous transmitter release from the presynaptic neuron as an anterograde signal for recruiting postsynaptic mechanisms of ITF and LTF. 5-HT produced a substantial increase in the frequency of spontaneous miniature excitatory postsynaptic currents (mEPSCs) and a more modest increase in their amplitude during, or shortly after, the induction of ITF or LTF in cell culture. Those increases correlated with subsequent facilitation of the evoked EPSP, consistent with the idea that spontaneous release contributes to the induction of the facilitation. In support of that idea, several manipulations that either reduced or enhanced spontaneous release (without affecting baseline evoked release) also reduced or enhanced ITF and LTF. These results 
suggested that spontaneous release is necessary for the induction of ITF and LTF, and acts synergistically with additional mechanisms (activated, e.g., by presynaptic cAMP) to produce the facilitation.

Further experiments showed that spontaneous release from the presynaptic neuron activates metabotropic glutamate receptors, which stimulate IP3 production and $\mathrm{Ca}^{2+}$ release in the postsynaptic neuron (Fig. 2). In addition, expression of the latter part of facilitation may involve up-regulation of AMPA-like receptors (see also Li et al. 2005). To examine that mechanism more directly, Jin et al. (2012b) expressed the Aplysia homolog of the AMPA receptor subunit GluR1 in the MN. The application of 5-HT for $10 \mathrm{~min}$ produced an increase in membrane insertion of ApGluR1 into existing puncta as well as increases in the number of puncta of ApGluR1 and overlap with puncta of the presynaptic protein synaptophysin. Furthermore, all of those increases depended on spontaneous release and/or mGluRs. The increase in ApGluR1 puncta during ITF preceded an increase in synaptophysin puncta (Kim et al. 2003), and, therefore, may be a first step in a sequence that can lead to new synapse assembly during LTF.

\section{LONG-TERM SENSITIZATION}

Neuronal Correlates of Long-Term Sensitization

In addition to STS and ITS, withdrawal reflexes can also display LTS, lasting from several hours to weeks (Pinsker et al. 1973). Although STS (or its in vitro analogue STF) can be induced by brief treatments (lasting a few seconds to minutes), LTS- and 5-HT-induced LTF require more extensive training involving multiple trials spaced over hours or days.

One approach to investigating mechanisms of LTS is to examine its neural correlates - that is, to train an animal, remove the nervous system some time later, and test for differences in cellular properties compared with controls. Such studies have shown that mechanisms supporting LTS generally resemble the mechanisms sup- porting STS including changes in SN excitability (long-term enhanced excitability [LTEE]) and facilitation of sensorimotor synapses (i.e., LTF) (Frost et al. 1985; Scholz and Byrne 1987; Cleary et al. 1998). However, although STS is correlated with SN spike broadening, LTS is correlated with SN spike narrowing (Antzoulatos and Byrne 2007). The functional implications of spike narrowing are not obvious, but may involve an increase in the fidelity of the neuronal response to peripheral stimuli by decreasing the probability of spike failures. Another key difference between cellular correlates of STS and LTS is that LTS is associated with structural modifications of SNs, namely, outgrowth of neurites and remodeling of active zones, whereas STS is not. These data suggest that enhanced transmission is mediated by an increase in transmitter release and in number of synapses (Bailey and Chen 1983; Wainwright et al. 2002). LTS and LTF are also correlated with enhanced uptake of glutamate (Levenson et al. 2000), the endogenous transmitter of SNs (Dale and Kandel 1993; Antzoulatos and Byrne 2004). In addition, LTS is correlated with changes in the biophysical properties of MNs (Cleary et al. 1998), and an increased synthesis of postsynaptic receptors (Trudeau and Castellucci 1995; Zhu et al. 1997; Cai et al. 2008).

Molecular Mechanisms Contributing to the Induction of LTF-cAMP-Response ElementBinding (CREB) and Gene Regulation

The molecular mechanisms of LTF have been examined more extensively in neural analogs in isolated ganglia or cell culture (Fig. 3). Such studies have shown that STF and LTF share some common cellular pathways during their induction. For example, both forms activate the cAMP/PKA cascade. However, although STF involves PKA-dependent covalent modifications of proteins involved in increasing spike width, excitability, and transmitter release, LTF involves the PKA-dependent regulation of gene transcription and new protein synthesis. Multiple training trials or repeated applications of 5-HT lead to a translocation of PKA to the nucleus, where it phosphorylates the transcriptional ac- 


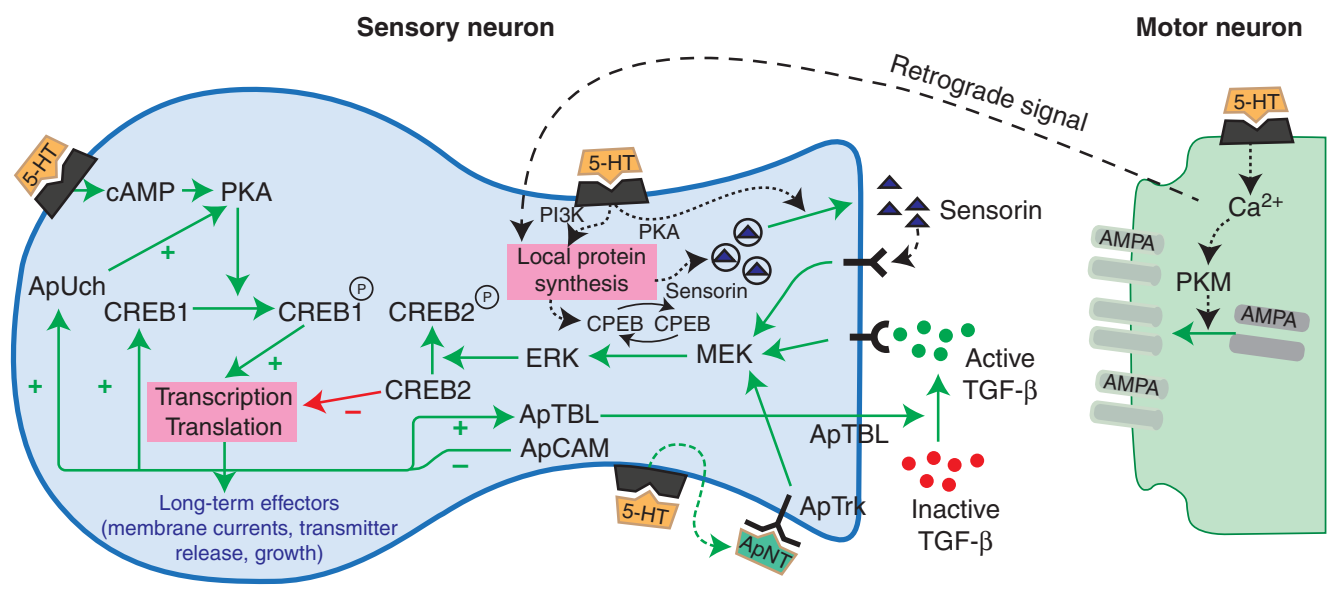

Figure 3. Simplified scheme of the mechanisms that contribute to long-term sensitization in Aplysia. Sensitization training leads to cyclic adenosine 3-monophosphate (cAMP)-dependent regulation of cAMP-response element binding (CREB)1. Serotonin also leads to activation of extracellular signal-regulated kinase (ERK), which regulates CREB2. Although CREB1 acts as an initiator of gene transcription, CREB2 acts as a repressor of gene transcription. The combined effects of activation of CREB1 and suppression of CREB2 lead to regulation of the synthesis of at least 10 proteins, only some of which are shown. Aplysia tolloid/BMP-like protein (ApTBL) is believed to activate latent forms of transforming growth factor (TGF)- $\beta$, which can then bind to receptors on the sensory neuron (SN). TGF- $\beta$ activates ERK, which may act by initiating a second round of gene regulation by affecting CREB2-dependent pathways. Serotonin can also increase the local synthesis of the Aplysia homolog of cytoplasmic polyadenylation element-binding protein (ApCPEB) and the peptide sensorin through phosphoinositide-3-kinase (PI3K). ApCPEB can exist in two conformations, one of which dominates and allows ApCPEB to self-perpetuate. Sensorin release is dependent on type II protein kinase A (PKA). Sensorin binds to autoreceptors leading to further activation of ERK. Because increased synthesis of sensorin requires elevation of postsynaptic calcium, a retrograde signal is also postulated. In addition to the retrograde signal, 5-HTinduced postsynaptic signaling also leads to an increased number of glutamate receptors. AMPA, $\alpha$-amino-3hydroxy-5-methyl-4-isoxazolepropionic acid; ApCAM, Aplysia cell adhesion molecule; ApTrk, Aplysia tyrosine kinase autoreceptor; ApUch, Aplysia ubiquitin hydrolase; MEK, MAPK/ERK kinase; PKM, protein kinase M. (Based on data from Liu et al. 1997.)

tivator cAMP-responsive element-binding protein (CREB1). CREB1 binds to a regulatory region of genes known as CRE (cAMP-responsive element). A second transcription factor CREB2 also binds to the CRE, but unlike CREB1, CREB2 is a repressor of gene transcription. $\mathrm{Al}-$ though CREB1 is activated by PKA, CREB2 is inhibited in parallel by a 5-HT-induced increase in extracellular signal-regulated kinase (ERK) phosphorylation. In addition, CREB2 levels are reduced by a piRNA, which is a type of small regulatory RNA that can control gene expression through epigenetic mechanisms (Rajasethupathy et al. 2012). The role of transcription factors in long-term memory formation is not limited to the induction phase but may also extend to the consolidation phase, where consoli- dation is defined as the time window during which RNA and protein synthesis are required for converting short- to long-term memory. For example, treatment of ganglia with five pulses of 5-HTover a 1.5 -h period to mimic sensitization training leads to the binding of CREB1 to the promoter of its own gene and induces CREB1 synthesis, giving rise to a CREB1-positive feedback loop that supports memory consolidation (Liu et al. 2011).

\section{Feedback Loops also Contribute to LTF}

As illustrated by the CREB1 feedback loop, the phosphorylation of CREB1 by PKA and CREB2 by ERK is not a simple serial cascade starting with binding of 5-HT to membrane receptors. 
Indeed, the transduction process involves multiple feedback pathways. For example, levels of Aplysia ubiquitin hydrolase (ApUch) in SNs are increased, possibly via a CREB-based increase in ApUch transcription. The increased levels of ApUch increase the rate of degradation of proteins, via the ubiquitin-proteosome pathway, including the regulatory subunit of PKA (Chain et al. 1999). The catalytic subunit of PKA, when freed from the regulatory subunit, is highly active. Thus, increased ApUch triggered by the initial treatment of SNs with 5-HT will lead to an increase in PKA activity and a more protracted phosphorylation of CREB1 (Fig. 3). This phosphorylated CREB1 may act to further prolong ApUch expression, thus closing a positive feedback loop. Protein degradation, in general, and the role of ubiquitination in particular, is an emerging theme in recent studies on the neural basis of long-term memory (Fioravante and Byrne 2011).

Several extracellular feedback cascades also appear to operate to activate ERK and, thereby, regulate CREB2 (Martin et al. 1997; Guan et al. 2002). 5-HT stimulates secretion of a recently identified endogenous Aplysia neurotrophin (ApNT) from the SN (Kassabov et al. 2013), leading to the activation of an Aplysia tyrosine kinase autoreceptor (ApTrk) and subsequent activation of ERK in the SN (Fig. 3) (Purcell et al. 2003; Ormond et al. 2004; Sharma et al. 2006). A similar feedback loop occurs through the release of an Aplysia cysteine-rich neurotrophic factor (ApCRNF) (Pu et al. 2014). 5-HT also acts through feedback pathways involving the peptides sensorin and transforming growth factor (TGF)- $\beta$. A role for TGF- $\beta$ was originally hypothesized based on the finding that LTF is associated with an increased expression of Aplysia tolloid/BMP-like (ApTBL)-1 protein. Tolloid and the related molecule BMP-1 appear to function as secreted $\mathrm{Zn}^{2+}$ proteases, which activate members of the TGF- $\beta$ family in some systems. In SNs, application of TGF- $\beta$ mimics the effects of 5-HT in that it produces LTF (Fig. 3) (Zhang et al. 1997). Interestingly, TGF- $\beta$ activates ERK in the SNs and induces its translocation to the nucleus. Thus, TGF- $\beta$ could be part of an extracellular positive feedback loop, possibly leading to another round of protein synthesis to further consolidate the memory (Zhang et al. 1997).

Another extracellular positive feedback loop that affects ERK involves the 5-HT-induced regulation of the release of the $\mathrm{SN}$-specific neuropeptide sensorin (Fig. 3). Synthesis of sensorin is stimulated by 5-HT in a PI3 (phosphatidylinositol-3)-kinase-dependent manner, and sensorin binding to presynaptic autoreceptors activates ERK. Sensorin synthesis also requires elevation of postsynaptic calcium (Cai et al. 2008). The mechanism through which postsynaptic calcium regulates the local protein synthesis of sensorin in the presynaptic terminal is not fully understood, but presumably involves the release of a retrograde signal (Cai et al. 2008). Although the presence of a postsynaptic neuron seems to be required for long-term facilitation, it is not required for another correlate of longterm sensitization, increased SN excitability (Cleary et al. 1998; Liu et al. 2011). Thus, accumulating evidence suggests that expression of long-term memory in this simple system does not rely on a unitary mechanism, but on multiple mechanisms at multiple sites.

\section{Molecules Involved in the Maintenance and Expression of LTF}

The combined effects of activation of CREB1 and removal of the repression of transcription by CREB2 lead to changes in the synthesis of specific proteins that allow for the maintenance and expression of LTF. The down-regulation of a homolog of a neuronal cell adhesion molecule (NCAM) shows that ApCAM plays a key role in the expression of long-term facilitation. This down-regulation has two components. First, the synthesis of ApCAM is reduced (Fig. 3). Second, preexisting ApCAM is internalized via increased endocytosis (not shown). The internalization and degradation of ApCAM allow for the restructuring of the axon arbor (Bailey and Kandel 2008). This restructuring allows the SN to form additional connections with the $\mathrm{MN}$ or with other cells. Structural changes associated with LTF also involve the presynaptic cell-adhesion protein neurexin, along with its postsynap- 
J.H. Byrne and R.D. Hawkins

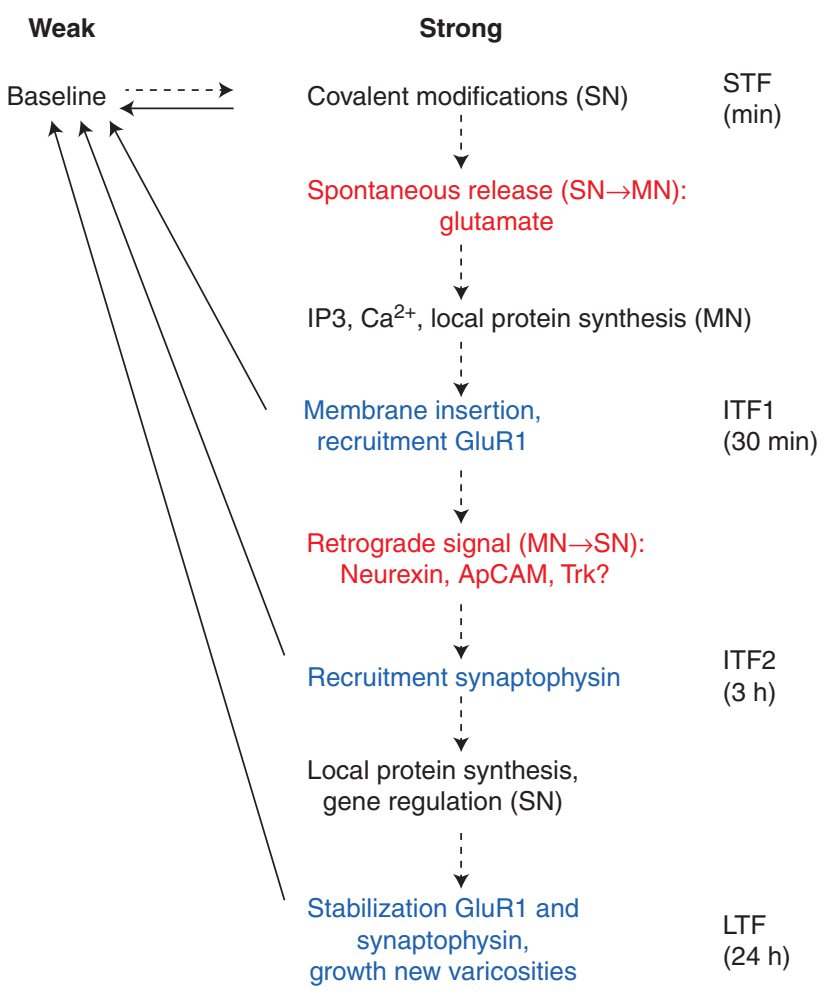

Figure 4. Cascade model of mechanisms contributing to the different stages of synaptic plasticity in Aplysia. In cascade models (Fusi et al. 2005), synapses have two levels of strength (weak and strong) and several increasingly long-lasting states. In Aplysia, relatively weak stimulation produces short-term facilitation (STF) that lasts minutes, stronger stimulation produces intermediate-term facilitation (ITF) that lasts minutes to hours, and even stronger stimulation produces long-term facilitation (LTF) that lasts days. The different stages of facilitation may involve a series or cascade of pre- and postsynaptic mechanisms that is initiated by spontaneous transmitter release during STF, progresses through two stages of ITF, and can culminate in synaptic growth during LTF. The mechanisms in this growth cascade are a subset of all mechanisms involved in facilitation, and some other mechanisms (not shown) may act in parallel and contribute only to specific stages. Thus, the idea of a cascade applies to the mechanisms and not the stages per se. In addition to this linear cascade, facilitation also involves feedforward and feedback loops. Dashed lines, transitions that are initiated by different durations or patterns of 5-HT; solid lines, spontaneous transitions; red, extracellular signaling molecules; blue, structural modifications. $\mathrm{MN}$, motor neuron; SN, sensory neuron.

tic counterpart neuroligin and their transsynaptic interaction (Choi et al. 2011).

In addition, the persistence of LTF depends on two molecules that can maintain a change in functional state for long periods of time. First, the stabilization of new structures depends on the Aplysia homolog of cytoplasmic polyadenylation element-binding protein (ApCPEB) (Miniaci et al. 2008), which regulates local translation in the SNs (Fig. 3). ApCPEB has prion-like properties, meaning that it can exist in two conformations, one of which dominates and allows ApCPEB to self-perpetuate. Conversion of ApCPEB to the self-perpetuating state is enhanced by $5-\mathrm{HT}$ and is required for the persistence of LTF ( $\mathrm{Si}$ et al. 2010). Second, as discussed earlier for ITF, the persistence of LTF also depends on the persistent activation of PKC by cleavage to the PKM form (PKM Apl III) (Cai et al. 2011), which is thought to regulate the membrane insertion of AMPA receptors in the MN (Fig. 3). 
Possible Relationships between Mechanisms Contributing to STF, ITF, and LTF

Collectively, the results on STF, ITF, and LTF in Aplysia suggest that, like synapse formation (McAllister 2007), the different stages of synaptic plasticity may involve different pre- and postsynaptic mechanisms coordinated by backand-forth signaling in a chain or cascade that can culminate in growth (Fig. 4). Consistent with that idea, spontaneous transmitter release from the presynaptic neuron during STF recruits postsynaptic molecular mechanisms of ITF including IP3, $\mathrm{Ca}^{2+}$, and formation of clusters of AMPA-like glutamate receptors. Postsynaptic $\mathrm{Ca}^{2+}$ is, in turn, necessary for LTF, perhaps through retrograde signaling to presynaptic ApCAM, neurexin, or Trk receptors (Purcell et al. 2003; Ormond et al. 2004; Sharma et al. 2006; Cai et al. 2008; Hu et al. 2010; Choi et al. 2011; Kassabov et al. 2013). The new postsynaptic clusters of AMPA-like receptors may also participate in retrograde signaling, and recruit presynaptic clusters of synaptophysin during a later stage of ITF and growth of presynaptic varicosities during LTF (Kim et al. 2003; Ripley et al. 2011; Lee et al. 2012). These ideas are similar to theoretical "cascade" models of memory storage that can show plasticity as well as long-term stability (Fusi et al. 2005), which would seem to be mutually exclusive but are both essential features of memory. In addition to this linear cascade, the mechanisms of plasticity also form feedforward loops involved in synaptic "tagging," which allows transcription-dependent LTF to be synapse specific (Casadio et al. 1999), as well as feedback loops involved in the long-term persistence of the functional and structural changes (Fig. 3).

\section{NEURAL AND MOLECULAR MECHANISMS OF NONASSOCIATIVE LEARNING IN OTHER INVERTEBRATE MODEL SYSTEMS}

Analyses of nonassociative learning in other invertebrates have confirmed and extended the work on Aplysia. Thus, as in Aplysia (Castellucci et al. 1970; Castellucci and Kandel 1974), habituation in crayfish (Zucker 1972) and several oth- er species (see below) appears to be caused by a progressive decrease in the amount of transmitter released by primary sensory neurons. In addition, there is apparent conservation of molecular mechanisms for sensitization, which often involve the engagement of 5-HT and the cAMP cascade. For example, the opisthobranch Tritonia diomedea initiates stereotypical rhythmic swimming to escape a noxious stimulus. The behavior shows both habituation and sensitization (Frost et al. 1996). Habituation appears to involve plasticity at multiple loci, including decrement at the first afferent synapse. Sensitization appears to involve enhanced excitability and synaptic strength in one of the central pattern-generating (CPG) interneurons. Modulation of interneurons can be mediated by $5-\mathrm{HT}$, which has diverse effects on multiple loci of the circuit (Sakurai et al. 2007). Sensitization of withdrawal reflexes of the land snail Helix also appears to be mediated by serotonergic modulatory cells whose spiking frequency increases following noxious stimulation (Balaban 2002). These serotonergic cells are electrically coupled so that they are recruited and fire synchronously in response to strong excitatory input.

The shortening reflex of the leech Hirudo medicinalis shows habituation and sensitization, and the neuronal changes underlying both occur in the pathway from mechanosensory neurons to the S cells (Sahley et al. 1994). Habituation correlates with decreased S-cell excitability (Burrell et al. 2001) and the reflex can be restored (dishabituation) following application of a single noxious stimulus (Boulis and Sahley 1988). The potentiation of the shortening reflex observed during sensitization is mediated by 5 -HT through an increase of the levels of cAMP (Belardetti et al. 1982; Burrell and Sahley 2005), which also increases the excitability of S cells and spike after hyperpolarization (AHP) (Burrell et al. 2001; Burrell and Crisp 2008).

Habituation of the shortening reflex also involves depression of the synapses of touch (T) sensory neurons onto their follower target neurons. This synaptic depression is associated with an increase in the amplitude of the T-cell AHP that follows their discharge (Brunelli et al. 1997; 
Scuri et al. 2002). The persistent increase in AHP amplitude, following low-frequency stimulation of $\mathrm{T}$ cells, has been attributed to increased activity of the electrogenic $\mathrm{Na}^{+}$pump, and requires activation of phospholipase A2 (Scuri et al. 2005; Zaccardi et al. 2012).

Nonassociative learning has been studied extensively in C. elegans by Catharine Rankin and colleagues. C. elegans is a valuable model system for cellular and molecular studies of learning because it has an extremely simple nervous system that consists of a total of 302 neurons, the anatomical connectivity of which has been described at the electron microscopy level. C. elegans responds to a vibratory stimulus applied to the medium in which they locomote by swimming backward. This reaction, known as the tap withdrawal reflex, shows habituation, dishabituation, sensitization, and long-term $(24 \mathrm{~h})$ retention of habituation training. Laser ablation studies have been used to elucidate the neural circuitry supporting the tap withdrawal reflex and to identify likely sites of plasticity within the network. Plastic changes during habituation appear to occur at the chemical synapses between presynaptic sensory neurons and postsynaptic command interneurons. Analysis of several C. elegans mutants has revealed that synapses at the locus of plasticity in the network may be glutamatergic (Ardiel and Rankin 2010; Bozorghmehr et al. 2013). CREB is required for long-term but not short-term habituation (Timbers and Rankin 2011).

\section{SUMMARY AND CONCLUSIONS}

The simplicity and tractability of the neural circuits mediating behaviors in invertebrates have facilitated the cellular/molecular dissection of the underlying neural mechanisms of nonassociative learning and has illuminated several basic principles:

- Learning and memory rely on multiple mechanisms of plasticity at multiple sites of the neuronal circuits.

- The relative contribution to memory of the different sites varies as a function of the extent of training and time after training.
- Although the target proteins are different, the same intracellular signaling cascades that induce short-term modifications in synaptic transmission can also be used to induce long-term changes.

- Short-term memory relies on covalent modifications of preexisting proteins, but longterm memory also requires regulated gene transcription and translation.

- The induction of long-term memory requires both the activation of inducing signals, and the inhibition of inhibitory constraints imposed by other molecular pathways.

- Maintenance of long-term cellular memory involves both intracellular and extracellular feedback loops, which sustain the regulation of gene expression and the modification of targeted molecules.

- As described by Hawkins and Byrne (2015), associative forms of learning and memory can arise from the neural mechanisms that are used for nonassociative learning.

Since the 1960s, research on nonassociative learning in invertebrates has provided a wealth of information on the mechanisms of simple forms of learning. Although the learning studied is of the simplest type, the mechanisms have proven to be extremely rich and complex. The studies have provided important general principles that have proven applicable to all animals. Despite the great progress, the knowledge of memory mechanisms is still in its infancy. A more mature understanding will come from continued analyses of these model systems.

\section{ACKNOWLEDGMENTS}

Preparation of this manuscript was supported by National Institutes of Health (NIH) Grants GM097502, NS019895, and NS083690.

\section{REFERENCES \\ ${ }^{*}$ Reference is also in this collection.}

Antonov I, Kandel ER, Hawkins RD. 1999. The contribution of facilitation of monosynaptic PSPs to dishabituation 
and sensitization of the Aplysia siphon withdrawal reflex. J Neurosci 19: 10438-10450.

Antonov I, Kandel ER, Hawkins RD. 2010. Presynaptic and postsynaptic mechanisms of synaptic plasticity and metaplasticity during intermediate-term memory formation in Aplysia. J Neurosci 30: 5781-5791.

Antzoulatos EG, Byrne JH. 2004. Learning insights transmitted by glutamate. Trends Neurosci 27: 555-560.

Antzoulatos EG, Byrne JH. 2007. Long-term sensitization training produces spike narrowing in Aplysia sensory neurons. J Neurosci 27: 676-683.

Ardiel EL, Rankin CH. 2010. An elegant mind: Learning and memory in Caenorhabditis elegans. Learn Mem 17: 191 201.

Bailey CH, Chen M. 1983. Morphological basis of long-term habituation and sensitization in Aplysia. Science 220: $91-$ 93.

Bailey CH, Kandel ER. 2008. Synaptic remodeling, synaptic growth and the storage of long-term memory in Aplysia. Prog Brain Res. 169: 179-198.

Bailey CH, Montarolo P, Chen M, Kandel ER, Schacher S. 1992. Inhibitors of protein and RNA synthesis block structural changes that accompany long-term heterosynaptic plasticity in Aplysia. Neuron 9: 749-758.

Balaban PM. 2002. Cellular mechanisms of behavioral plasticity in terrestrial snail. Neurosci Biobehav Rev 26: 597 630.

Belardetti F, Biondi C, Colombaioni L, Brunelli M, Trevisani A. 1982. Role of serotonin and cyclic AMP on facilitation of the fast conducting system activity in the leech Hirudo medicinalis. Brain Res 246: 89-103.

Bougie JK, Lim T, Farah CA, Manjunath V, Nagakura I, Ferraro GB, Sossin WS. 2009. The atypical protein kinase $\mathrm{C}$ in Aplysia can form a protein kinase $\mathrm{M}$ by cleavage. J Neurochem 109: 1129-1143.

Bougie JK, Cai D, Hastings M, Farah CA, Chen S, Fan X, McCamphill PK, Glanzman DL, Sossin WS. 2012. Serotonin-induced cleavage of the atypical protein kinase $\mathrm{C}$ Apl III in Aplysia. J Neurosci 32: 14630-14640.

Boulis NM, Sahley CL. 1988. A behavioral analysis of habituation and sensitization of shortening in the semi-intact leech. J Neurosci 8: 4621-4627.

Bozorgmehr T, Ardiel EL, McEwan AH, Rankin CH. 2013. Mechanisms of plasticity in a Caenorhabditis elegans mechanosensory circuit. Front Physiol 4: 88

Brunelli M, Castellucci V, Kandel ER. 1976. Synaptic facilitation and behavioral sensitization in Aplysia: Possible role of serotonin and cyclic AMP. Science 194: 11781181.

Brunelli M, Garcia-Gil M, Mozzachiodi R, Scuri R, Zaccardi ML. 1997. Neurobiological principles of learning and memory. Arch Ital Biol 135: 15-36.

Burrell BD, Crisp KM. 2008. Serotonergic modulation of afterhyperpolarization in a neuron that contributes to learning in the leech. J Neurophysiol 99: 605-616.

Burrell BD, Sahley CL. 2005. Serotonin mediates learninginduced potentiation of excitability. J Neurophysiol 94: 4002-4012.

Burrell BD, Sahley CL, Muller KJ. 2001. Non-associative learning and serotonin induce similar bi-directional changes in excitability of a neuron critical for learning in the medicinal leech. J Neurosci 21: 1401-1412.

Byrne JH. 1987. Cellular analysis of associative learning. Physiol Rev 67: 329-439.

Byrne JH, Kandel ER. 1996. Presynaptic facilitation revisited: State and time dependence. J Neurosci 16: 435-435.

Cai D, Chen S, Glanzman DL. 2008. Postsynaptic regulation of long-term facilitation in Aplysia. Curr Biol 18: 920925.

Cai D, Pearce K, Chen S, Glanzman DL. 2011. Protein kinase $\mathrm{M}$ maintains long-term sensitization and long-term facilitation in Aplysia. J Neurosci 31: 6421-6431.

Carew TJ, Castellucci VF, Kandel ER. 1971. An analysis of dishabituation and sensitization of the gill-withdrawal reflex in Aplysia. Int J Neurosci 2: 79-98.

Casadio A, Martin KC, Giustetto M, Zhu H, Chen M, Bartsch D, Bailey CH, Kandel ER. 1999. A transient, neuron-wide form of CREB-mediated long-term facilitation can be stabilized at specific synapses by local protein synthesis. Cell 99: 221-237.

Castellucci VF, Kandel ER. 1974. A quantal analysis of the synaptic depression underlying habituation of the gillwithdrawal reflex in Aplysia. Proc Natl Acad Sci 71: 5004-5008.

Castellucci V, Pinsker H, Kupfermann I, Kandel ER. 1970. Neuronal mechanisms of habituation and dishabituation of the gill-withdrawal reflex in Aplysia. Science 167: $1745-1748$.

Chain DG, Casadio A, Schacher S, Hegde AN, Valbrun M, Yamamoto N, Goldberg AL, Bartsch D, Kandel ER, Schwartz JH. 1999. Mechanisms for generating the autonomous cAMP-dependent protein kinase required for long-term facilitation in Aplysia. Neuron 22: 147-156.

Chitwood RA, Li Q, Glanzman DL. 2001. Serotonin facilitates AMPA-type responses in isolated siphon motor neurons of Aplysia in culture. J Physiol 534: 501-510.

Choi YB, Li HL, Kassabov SR, Jin I, Puthanveettil SV, Karl KA, Lu Y, Kim JH, Bailey CH, Kandel ER. 2011. Neurexinneuroligin trans-synaptic interaction mediates learningrelated synaptic remodeling and long-term facilitation in Aplysia. Neuron 70: 468-481.

Cleary LJ, Lee WL, Byrne JH. 1998. Cellular correlates of long-term sensitization in Aplysia. J Neurosci 18: 59885998.

Dale N, Kandel ER. 1993. L-glutamate may be the fast excitatory transmitter of Aplysia sensory neurons. Proc Natl Acad Sci 90: 7163-7167.

Emptage NJ, Carew TJ. 1993. Long-term synaptic facilitation in the absence of short-term facilitation in Aplysia neurons. Science 262: 253-256.

Fioravante D, Byrne JH. 2011. Protein degradation and memory formation. Brain Res Bull 85: 14-20.

Frost WN, Castellucci VF, Hawkins RD, Kandel ER. 1985. Monosynaptic connections made by the sensory neurons of the gill- and siphon-withdrawal reflex in Aplysia participate in the storage of long-term memory for sensitization. Prod Natl Acad Sci 82: 8266-8269.

Frost WN, Brown GD, Getting PA. 1996. Parametric features of habituation of swim cycle in the marine mollusc Tritonia diomedea. Neurobiol Learn Mem 65: 125-135. 
J.H. Byrne and R.D. Hawkins

Fusi S, Drew PJ, Abbott LF. 2005. Cascade models of synaptically stored memories. Neuron 45: 599-611.

Ghirardi M, Montarolo PG, Kandel ER. 1995. A novel intermediate stage in the transition between short- and long-term facilitation in the sensory to motor neuron synapses of Aplysia. Neuron 14: 413-420.

Glanzman DL, Mackey SL, Hawkins RD, Dyke AM, Lloyd PE, Kandel ER. 1989. Depletion of serotonin in the nervous system of Aplysia reduces the behavioral enhancement of gill withdrawal as well as the heterosynaptic facilitation produced by tail shock. J Neurosci 9: 42004213.

Guan Z, Giustetto M, Lomvardas S, Kim JH, Miniaci MC, Schwartz JH, Thanos D, Kandel ER. 2002. Integration of long-term-memory-related synaptic plasticity involves bidirectional regulation of gene expression and chromatin structure. Cell 111: 483-493.

* Hawkins RD, Byrne JH. 2015. Associative learning in invertebrates. Cold Spring Harb Perspect Biol doi: 10.1101/ cshperspect.a021709.

Hawkins RD, Clark GA, Kandel ER. 1987. Cell biological studies of learning in simple vertebrate and invertebrate systems. In Handbook of physiology, section 1: The nervous system, Vol. V, Higher functions of the brain (ed. Mountcastle VB, Plum F, Geiger SR), pp. 25-83. American Physiological Society, Bethesda, MD.

Hawkins RD, Kandel ER, Bailey CH. 2006. Molecular mechanisms of memory storage in Aplysia. Biol Bull 210: 174 191.

Hawkins RD, Antonov I, Jin I. 2013. Mechanisms of shortterm and intermediate-term memory in Aplysia. In Invertebrate learning and memory (ed. Menzel R, Benjamin P), pp. 194-205. Academic, London.

Hu JY, Chen Y, Bougie JK, Sossin WS, Schacher S. 2010 Aplysia cell adhesion molecule and a novel protein kinase $\mathrm{C}$ activity in the postsynaptic neuron are required for presynaptic growth and initial formation of specific synapses. J Neurosci 30: 8353-8366.

Jin I, Hawkins RD. 2003. Presynaptic and postsynaptic mechanisms of a novel form of homosynaptic potentiation at Aplysia sensory-motor neuron synapses. J Neurosci 23: 7288-7297.

Jin I, Kandel ER, Hawkins RD. 2011. Whereas short-term facilitation is presynaptic, intermediate-term facilitation involves both presynaptic and postsynaptic protein kinases and protein synthesis. Learn Mem 18: 96-102.

Jin I, Puthenveettil S, Udo H, Karl K, Kandel ER, Hawkins RD. 2012a. Spontaneous transmitter release is critical for the induction of long-term and intermediate-term facilitation in Aplysia. Proc Natl Acad Sci 109: 9131-9136.

Jin I, Udo H, Rayman JB, Puthenveettil S, Vishwasrao HD, Kandel ER, Hawkins RD. 2012b. Postsynaptic mechanisms recruited by spontaneous transmitter release during long-term and intermediate-term facilitation in Aplysia. Proc Natl Acad Sci 109: 9137-9142.

Kassabov SR, Choi YB, Karl KA, Vishwasrao HD, Bailey CH, Kandel ER. 2013. A single Aplysia neurotrophin mediates synaptic facilitation via differentially processed isoforms. Cell Rep 3: 1213-1227.

Kim J-H, Udo H, Li H-L, Toun TY, Chen M, Kandel ER, Bailey CH. 2003. Presynaptic activation of silent synapses and growth of new synapses contribute to intermediate and long-term facilitation in Aplysia. Neuron 40: 151165.

Kruger KE, Sossin WS, Sacktor TC, Bergold PJ, Beushausen S, Schwartz JH. 1991. Cloning and characterization of $\mathrm{Ca}^{2+}$-dependent and $\mathrm{Ca}^{2+}$-independent PKCs expressed in Aplysia sensory cells. J Neurosci 11: 2302-2313.

Lee SJ, Uemura T, Yoshida T, Mishina M. 2012. GluRס2 assembles four neurexins into trans-synaptic triad to trigger synapse formation. J Neurosci 32: 4688-4701.

Levenson J, Endo S, Kategaya LS, Fernandez RI, Brabham DG, Chin L, Byrne JH, Eskin A. 2000. Long-term regulation of neuronal high-affinity glutamate and glutamine uptake in Aplysia. Proc Natl Acad Sci 97: 12858-12863.

Li Q, Roberts AC, Glanzman DL. 2005. Synaptic facilitation and behavioral dishabituation in Aplysia: Dependence on release of $\mathrm{Ca}^{2+}$ from postsynaptic intracellular stores, postsynaptic exocytosis, and modulation of postsynaptic AMPA receptor efficacy. J Neurosci 25: 5623-5637.

Li HL, Huang BS, Vishwasrao H, Sutedja N, Chen W, Jin I, Hawkins RD, Bailey CH, Kandel ER. 2009. Dscam mediates remodeling of glutamate receptors in Aplysia during de novo and learning-related synapse formation. Neuron 61: 527-540.

Liu Q-R, Hattar S, Endo S, MacPhee K, Zhang H, Cleary LJ, Byrne JH, Eskin A. 1997. A developmental gene (Tolloid /BMP-1) is regulated in Aplysia neurons by treatments that induce long-term sensitization. J Neurosci 17: $755-$ 764.

Liu RY, Cleary LJ, Byrne JH. 2011. The requirement for enhanced CREB1 expression in consolidation of longterm synaptic facilitation and long-term excitability in sensory neurons of Aplysia. J Neurosci 31: 6871-6879.

Mackey SL, Kandel ER, Hawkins RD. 1989. Identified serotonergic neurons LCB1 and RCB1 in the cerebral ganglia of Aplysia produce presynaptic facilitation of siphon sensory neurons. J Neurosci 9: 4227-4235.

Marinesco S, Carew TJ. 2002. Serotonin release evoked by tail nerve stimulation in the CNS of Aplysia: Characterization and relationship to heterosynaptic plasticity. $J$ Neurosci 22: 2299-2312.

Martin KC, Michael D, Rose JC, Barad M, Casadio A, Zhu H, Kandel ER. 1997. MAP kinase translocates into the nucleus of the presynaptic cell and is required for longterm facilitation in Aplysia. Neuron 18: 899-912.

Mauelshagen J, Parker GR, Carew TJ. 1996. Dynamics of induction and expression of long-term synaptic facilitation in Aplysia. J Neurosci 16: 7099-7108.

McAllister AK. 2007. Dynamic aspects of CNS synapse formation. Annu Rev Neurosci 30: 425-450.

Miniaci MC, Kim JH, Puthanveettil SV, Si K, Zhu H, Kandel ER, Bailey CH. 2008. Sustained CPEB-dependent local protein synthesis is required to stabilize synaptic growth for persistence of long-term facilitation in Aplysia. Neuron 59: 1024-1036.

Ormond J, Hislop J, Zhao Y, Webb N, Vaillaincourt F, Dyer JR, Ferraro G, Barker P, Martin KC, Sossin WS. 2004 ApTrkl, a Trk-like receptor, mediates serotonin-dependent ERK activation and long-term facilitation in Aplysia sensory neurons. Neuron 44: 715-728.

Philips GT, Sherff CM, Menges SA, Carew TJ. 2011. The tailelicited tail withdrawal reflex of Aplysia is mediated cen- 
trally at tail sensory-motor synapses and exhibits sensitization across multiple temporal domains. Learn Mem 18: 272-282.

Pinsker HM, Hening WA, Carew TJ, Kandel ER. 1973. Longterm sensitization of a defensive withdrawal reflex in Aplysia. Science 182: 1039-1042.

Pu L, Kopec AM, Boyle HD, Carew TJ. 2014. A novel cystinerich neurotrophic factor in Aplysia facilitates growth, MAPK activation, and long-term synaptic facilitation. Learn Mem 21: 215-222.

Purcell AL, Sharma SK, Bagnall MW, Sutton MA, Carew TJ. 2003. Activation of a tyrosine kinase-MAPK cascade enhances the induction of long-term synaptic facilitation and long-term memory in Aplysia. Neuron 37: 473-484.

Rajasethupathy P, Antonov I, Sheridan R, Frey S, Sander C, Tuschl T, Kandel ER. 2012. A role for neuronal piRNAs in the epigenetic control of memory-related synaptic plasticity. Cell 149: 693-707.

Ripley B, Otto S, Tiglio K, Williams ME, Ghosh A. 2011. Regulation of synaptic stability by AMPA receptor reverse signaling. Proc Natl Acad Sci 108: 367-372.

Sahley CL, Modney BK, Boulis NM, Muller KJ. 1994. The S cell: An interneuron essential for sensitization and full dishabituation of leech shortening. J Neurosci 14: 6715-6721.

Sakurai A, Calin-Jageman RJ, Katz PS. 2007. Potentiation phase of spike timing-dependent neuromodulation by a serotonergic interneuron involves an increase in the fraction of transmitter release. J Neurophysiol 98: 1975-1987.

Scholz KP, Byrne JH. 1987. Long-term sensitization in Aplysia: Biophysical correlates in tail sensory neurons. Science 235: 685-687.

Scuri R, Mozzachiodi R, Brunelli M. 2002. Activity-dependent increase of the AHP amplitude in T sensory neurons of the leech. J Neurophysiol 88: 2490-2500.

Scuri R, Mozzachiodi R, Brunelli M. 2005. Role for calcium signaling and arachidonic acid metabolites in the activity-dependent increase of AHP amplitude in leech T sensory neurons. J Neurophysiol 94: 1066-1073.

Sharma SK, Sherff CM, Stough S, Hsuan V, Carew TJ. 2006. A tropomyosin-related kinase B ligand is required for ERK activation, long-term synaptic facilitation, and long-term memory in Aplysia. Proc Natl Acad Sci 103: 14206-14210.

Shobe JL, Zhao Y, Stough S, Ye X, Hsuan V, Martin KC, Carew TJ. 2009. Temporal phases of activity-dependent plasticity and memory are mediated by compartmentalized routing of MAPK signaling in Aplysia sensory neurons. Neuron 61: 113-125.

Si K, Choi YB, White-Grindley E, Majumdar A, Kandel ER. 2010. Aplysia CPEB can form prion-like multimers in sensory neurons that contribute to long-term facilitation. Cell 140: 421-435.

Sutton MA, Carew TJ. 2000. Parallel molecular pathways mediate expression of distinct forms of intermediateterm facilitation at tail sensory-motor synapses in Aplysia. Neuron 26: 219-231.
Sutton MA, Masters SE, Bagnall MW, Carew TJ. 2001. Molecular mechanisms underlying a unique intermediate phase of memory in Aplysia. Neuron 31: 143-154.

Sutton MA, Bagnall MW, Sharma SK, Shobe J, Carew TJ. 2004. Intermediate-term memory for site-specific sensitization in Aplysia is maintained by persistent activation of protein kinase C. J Neurosci 24: 3600-3609.

Thompson RF, Spencer WA. 1966. Habituation: A model phenomenon for the study of neuronal substrates of behavior. Psychol Rev 73: 16-43.

Timbers TA, Rankin CH. 2011. Tap withdrawal circuit interneurons require CREB for long-term habituation in Caenorhabditis elegans. Behav Neurosci 125: 560-566.

Trudeau LE, Castellucci VF. 1995. Postsynaptic modifications in long-term facilitation in Aplysia: Upregulation of excitatory amino acid receptors. J Neurosci 15: 1275-1284.

Villareal G, Li Q, Cai D, Glanzman DL. 2007. The role of rapid, local, postsynaptic protein synthesis in learningrelated synaptic facilitation in Aplysia. Curr Biol 17: 2073-2080.

Villareal G, Li Q, Cai D, Fink AE, Lim T, Bougie JK, Sossin WS, Glanzman DL. 2009. Role of protein kinase C in the induction and maintenance of serotonin-dependent enhancement of the glutamate response in isolated siphon motor neurons of Aplysia californica. J Neurosci 29: $5100-5107$.

Wainwright ML, Zhang H, Byrne JH, Cleary LJ. 2002. Localized neuronal outgrowth induced by long-term sensitization training in Aplysia. J Neurosci 22: 4132-4141.

Walters ET, Byrne JH, Carew TJ, Kandel ER. 1983a. Mechanoafferent neurons innervating tail of Aplysia: I. Response properties and synaptic connections. J Neurophysiol 50: 1522-1542.

Walters ET, Byrne JH, Carew TJ, Kandel ER. 1983b. Mechanoafferent neurons innervating tail of Aplysia: II. Modulation by sensitizing stimulation. J Neurophysiol 50: 1543-1559.

Zaccardi ML, Mozzachiodi R, Traina G, Brunelli M, Scuri R. 2012. Molecular mechanisms of short-term habituation in the leech Hirudo medicinalis. Behav Brain Res 229: 235-243.

Zhang F, Endo S, Cleary LJ, Eskin A, Byrne JH. 1997. Role of transforming growth factor- $\beta$ in long-term synaptic facilitation in Aplysia. Science 275: 1318-1320.

Zhao Y, Leal K, Abi-Farah C, Martin KC, Sossin WS, Klein M. 2006. Isoform specificity of PKC translocation in living Aplysia sensory neurons and a role for $\mathrm{Ca}^{2+}$-dependent PKC APL I in the induction of intermediate-term facilitation. J Neurosci 26: 8847-8856.

Zhu H, Wu F, Schacher S. 1997. Site-specific and sensory neuron-dependent increases in postsynaptic glutamate sensitivity accompany serotonin-induced long-term facilitation at Aplysia sensorimotor synapses. J Neurosci 17: 4976-4986.

Zucker RS. 1972. Crayfish escape behavior and central synapses: II. Physiological mechanisms underlying behavioral habituation. J Neurophysiol 35: 621-637. 


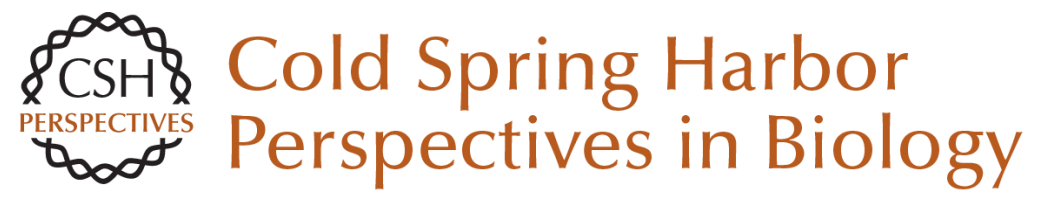

\section{Nonassociative Learning in Invertebrates}

John H. Byrne and Robert D. Hawkins

Cold Spring Harb Perspect Biol 2015; doi: 10.1101/cshperspect.a021675 originally published online February 26, 2015

\section{Subject Collection Learning and Memory}

Large-Scale Fluorescence Calcium-Imaging Methods for Studies of Long-Term Memory in Behaving Mammals Pablo Jercog, Thomas Rogerson and Mark J. Schnitzer

Exploring Memory Representations with

Activity-Based Genetics

Mark Mayford and Leon Reijmers

The Origins and Organization of Vertebrate

Pavlovian Conditioning Michael S. Fanselow and Kate M. Wassum

The Corticohippocampal Circuit, Synaptic

Plasticity, and Memory Jayeeta Basu and Steven A. Siegelbaum

Motor Learning and the Cerebellum Chris I. De Zeeuw and Michiel M. Ten Brinke

The Striatum: Where Skills and Habits Meet Ann M. Graybiel and Scott T. Grafton

Molecular Genetic Strategies in the Study of Corticohippocampal Circuits

Christopher C. Angelakos and Ted Abel

Nonassociative Learning in Invertebrates John H. Byrne and Robert D. Hawkins
The Role of Functional Prion-Like Proteins in the Persistence of Memory

Kausik Si and Eric R. Kandel

Working Memory: Maintenance, Updating, and the

Realization of Intentions

Lars Nyberg and Johan Eriksson

Memory Retrieval in Mice and Men Aya Ben-Yakov, Yadin Dudai and Mark R. Mayford

Reconsolidation and the Dynamic Nature of

Memory

Karim Nader

Memory Consolidation

Larry R. Squire, Lisa Genzel, John T. Wixted, et al.

Structural Components of Synaptic Plasticity and Memory Consolidation

Craig H. Bailey, Eric R. Kandel and Kristen M. Harris

Associative Learning in Invertebrates Robert D. Hawkins and John H. Byrne

The Regulation of Transcription in Memory Consolidation Cristina M. Alberini and Eric R. Kandel

For additional articles in this collection, see http://cshperspectives.cshlp.org/cgi/collection/

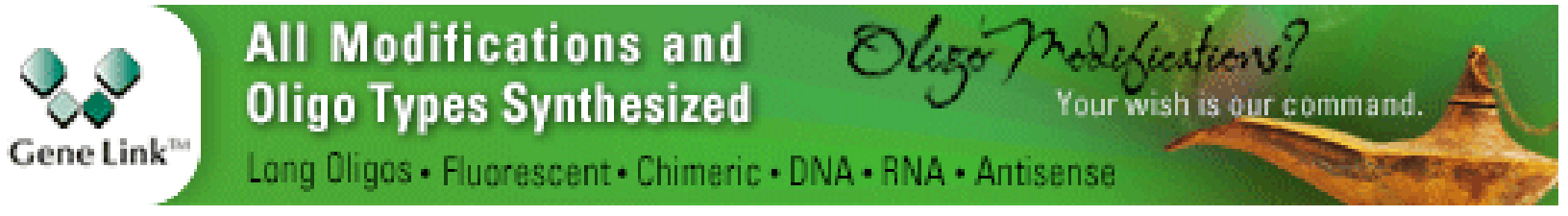

